\title{
The Influence of Students' Sociocultural Background on the IELTS Speaking Test Preparation Process
}

\author{
Galina Pavlovskaya \\ National Research University Higher School of Economics
}

\begin{abstract}
Correspondence concerning this article should be addressed to Galina Pavlovskaya, English Language Department for Economic and Mathematical Disciplines, National Research University Higher School of Economics, 26 Shabolovka Ulitsa, Room 4340, Moscow, 119043, Russiat Federation. E-mail: gpavlovskaya@hse.ru
\end{abstract}

\author{
Anastasia Lord \\ John Molson School of Business, Concordia University
}

\begin{abstract}
Correspondence concerning this article should be addressed to Anastasia Lord, John Molson School of Business, Concordia University, 1455 Boulevard de Maisonneuve O, Montréal, QC H3G 1M8, Canada.

E-mail: gpavlovskaya@hse.ru
\end{abstract}

\begin{abstract}
The article is aimed at highlighting the sociocultural factors a teacher/IELTS instructor should consider preparing Russian students for the IELTS exam. The main focus of the study was on four speech functions most frequently used in the IELTS Speaking Test: explaining and paraphrasing, expressing personal opinion, providing personal information, and summarizing. The study aims to question the assumption that the problems arising in the use of these speech functions are provoked by the students' low language level and to investigate if there are any sociocultural issues connected with the use of the above-mentioned speech functions influencing students' performance during the IELTS Speaking Test. The study was conducted among first-year students at the Higher School of Economics (HSE) in the Faculty of Computer Science. To see the problem from a different perspective, the study involved not only the firstyear students who seem to struggle with the speech functions but also their English teachers who can provide trustworthy first-hand information on the problems the students frequently face. The results of the study demonstrate that the cause of problems students encounter using the speech functions should not be attributed only to their language knowledge, as do the majority of interviewed teachers. The way students tend to explain, paraphrase, summarize, express their opinion and provide personal information is culturally defined which influences students' ability to perform these functions effectively. To help Russian students avoid sociocultural problems preparing for the IELTS Speaking Test, a teacher/IELTS instructor should aim to increase students' sociocultural awareness of the pitfalls in the use of the essential speech functions and sociocultural competence in a foreign language.
\end{abstract}

Keywords: IELTS, speech functions, sociocultural competence, intercultural communication, multicultural workplace environment

The ever-growing demand for the IELTS certificate, as one of the most valued and recognized by the international employers, is one of the powerful external factors encouraging the most established and forward-looking universities worldwide to provide their students with an opportunity to take the exam and, more importantly, to pass it. The students of the HSE having completed a two-year university English course are ready to take a full-scale IELTS exam with a competitive result (band 6.5-7.5). However, the process of preparation for the exam is demanding and challenging not only for the students themselves but also for their teachers who assume a large part of responsibility for a student's success. The significance of the sociocultural background of the IELTS exam preparation courses is recognized by the educators and researchers who admit the necessity of more detailed and advanced research into the field that still has a lot 
of controversial questions concerning the process of preparation and assessment (Gibson \& Swan, 2008; Murray, Cross, \& Cruickshank, 2014). The present study highlights the sociocultural background of the IELTS Speaking Test preparation and may be of relevance for IELTS instructors/examiners, teachers and researchers interested in finding ways of developing a learner's intercultural competence in a foreign language and sociocultural competence as its integral part.

Apart from the opportunity to work in multicultural companies, to study at top-ranked universities and to live in almost every corner of the world, globalization brings national conflicts and loss of identity. Nowadays an intercultural dialogue is often seen as the main remedy to help bridge cultural differences and to defuse the side effects of globalization (Byram, Nichols, \& Stevens, 2001; Deardorff, 2006). Intercultural communicative competence and its sociocultural component required for a productive intercultural dialogue have been proven to be a factor for success for multicultural teams that, thanks to IT technology, can be engaged not only in real faceto-face communication but also in a virtual one or a hybrid of both (Safonova, 2014). As reported by Neo HR organizing annual opinion polls among the students of top Russian universities, world-famous internationally active companies like Google, Microsoft, Yandex, EY, KPMG, Deloitte employ the largest number of the specialists in the field of IT and are considered to be the most reliable employers among Russian students, namely, the students of the Faculty of Computer Science at the Higher School of Economics (HSE) who participated in the study described further in this article. According to the annual reports published by the National Organization of Colleges and Employers (NACE), recruiting policy of these international companies requires that a successful candidate should provide valid academic qualifications proving his/ her professional skills, an internationally recognized certificate of English language proficiency for nonnative English language speakers, and, above all, demonstrate an ability to work in a multicultural team that depends greatly on the level of sociocultural competence.

According to Byram, Zarate and Neuner (1997), sociocultural competence includes an ability to relate to the representatives of other cultures, knowledge of their way of life, a capacity to enter and discover new situations of intercultural exchange, as well as awareness of self and of how people from different cultures see us. The lack of sociocultural competence may result in communication failures occurring due to numerous sociocultural pitfalls a FL learner fails to avoid. Regardless of the indisputable influence of sociocultural competence on the success of intercultural communication it is still paid modest attention. Highlighting the interconnection of sociocultural competence with other competences in a complex structure of an intercultural communicative competence, Byram and Zarate (1997) express their concern with the imbalance existing in the approach to linguistic and other competences: "In a context of foreign language learning we have to recognize language learning as the dominant concern of teachers and learners. This leads to distortion of the relationship between linguistic competences and others" (p. 10). This focus on linguistic competence often leads to a dysfunctional approach to language teaching, which Kramsch (2004) describes as teaching the four skills "plus culture". However, culture should be "viewed as enabling language proficiency and as being the outcome of reflection on language proficiency" (p. 8). As a result of this approach to language teaching, a student advanced in reading, listening, writing and speaking may still encounter the problem of misunderstanding, misinterpretation often leading to mutual stereotypes in the process of intercultural communication. Cultural differences may hinder effective communication and participation in group work and tutorial discussions, even among those who are proficient in English and come well prepared for classes (Mak, Westwood, Ishiyama, \& Barker, 2000; Paulus, Bichelmeyer, Malopinsky, \& Rastogi, 2005; Mak, 2011). Another challenge in store for foreign language learners as well as their teachers and examiners, who realize the importance of sociocultural competence and implement the principles of its development into practice, is the problem of assessment (Cohen \& Olshtain, 1981; Safonova, 2008; Holmes \& O’Neill, 2012). One more question that still remains unanswered is whether the IELTS exam helps to efficiently assess sociocultural competence and guarantee that the holder of the IELTS certificate fits into a multicultural team and satisfies an international employer's expectations. As outlined in the recent IELTS Research Report, there are "difficulties not directly attributed to language" and "it is important to examine these issues because the extent to which it is ethical for a language test to probe cultural aspects of workplace readiness remains a controversial question" (Murray, Cross, \& Cruickshank, 2014, p. 34). Obviously, "cultural aspects" are a matter of concern for the IELTS developers, however, as "a language test" it is not aimed at assessing sociocultural competence and be sufficient proof that a candidate will become a strong team player in a multicultural workplace environment. On the other hand, teachers and IELTS examiners have to face the sociocultural background their students inevitably bring into the classroom and take it into consideration, which can be a challenging task to perform given the fact that teachers frequently have no resources beyond the official IELTS handbook and 
some commercial materials (Gibson \& Swan, 2008).

While L2 teachers worldwide are struggling to examine existing teaching practices and explore the alternatives to guarantee greater achievements for their students, sociocultural background is frequently ignored though it is bound to come on stage in every classroom (Johnson, 2009). It happens not only when culture is discussed or taught explicitly but every time a foreign language learner uses the language (Kramsch, 2004; Elizarova, 2005) and when he/she performs one of the essential speech functions, such as analyzing, comparing and contrasting, explaining and paraphrasing, expressing and justifying opinion, providing personal information, summarising, etc. (Fulcher, 2003). Clearly, every foreign language learner draws from the sociocultural traditions and behavioral patterns in speaking and communication existing in his/her culture. The profound research into the sociocultural characteristics typical for Russian learners and their speaking behavior has been made in the works by Russian and foreign authors (Wierzbicka, 1997; Vassilieva, 1998; Leontovich, 2002; Sternina \& Sternin, 2003).

The focus of the conducted study, which is a survey, is on the IELTS Speaking Test, and namely, on the sociocultural issues influencing the students' ability to use the following speech functions: 1) explaining and paraphrasing, 2) expressing opinion, 3) summarising and 4) providing personal information. The survey aims to clarify whether the problems arising in the use of the speech functions are provoked by the students' low language level, as is generally assumed. The survey is guided by the following research questions:

1) What are the reasons for the inefficient use of the speech functions?

2) Are there any sociocultural factors influencing the use of the speech functions?

3) Are teachers' and students' perceptions of the reasons for the inefficient use of the speech functions aligned? If yes/no, to what extent?

\section{Materials and Methods}

\section{Participants}

The study was conducted at the Faculty of Computer Science at the HSE and involved 60 firstyear students studying for a Bachelor's degree in Software Engineering. The students' level of proficiency in English varied from B1 to C1 according to CEFR (Common European Framework of Reference for Languages). To see the problem from a different perspective 10 English language teachers working at the same faculty were interviewed about the difficulties their students have using the above-mentioned speech functions. Among the English teachers participating in the described study there were IELTS examiners, teachers obtaining DELTA, CELTA, TKT, CPE and IELTS certificates. The teachers and students are representatives of the Russian culture and are not expected to experience misunderstanding because of the cultural gap between them.

\section{Materials}

The materials for the study comprised a questionnaire for students and key-informant semistructured interviews with their English teachers. The survey included two procedures:

\section{Research Design}

\section{Step 1}

Students were offered a questionnaire specially developed for the study (see Appendix 1). The questionnaire included four parts focusing on the speech functions and had a structural pattern known as 'a questionnaire-an interview' (Valeev, 2002). In each of these four parts the students were offered four fixed alternatives to choose from and they were also asked to propose their own alternative and/or write their comments in the blank space provided. It is important to outline that students were free to choose more than one option from the questionnaire, and/or propose their own, as well as to comment upon their choice in a follow-up discussion.

\section{Step 2}

English teachers were invited for key-informant semi-structured interviews. The structural pattern of interviews used in the study can be described as a 'semi-structured interview', or as it is also called 'semistandardized' or 'in-depth and 'focused interview'; it is a data collection method widely used in language pedagogy research (Nunan, 1992; Brown, 1994). This structure for an interview helps a researcher to guide the whole process and have more control over the direction of the conversation than in an unstructured conversation; while the interviewed are not restricted by the questions, and on the contrary, are encouraged to give details and make their own assumptions. The questions asked by an interviewee in a semi-structured interview are traditionally classified as open, semiclosed, closed and questions/items with fixed alternatives (Cohen, 2007). The questions/guidelines used in the interviews with teachers in this study were formulated following this tradition and included all of the question types, such as: 1) "How would you describe the way your students express personal 
opinion?"; 2) "Do they have any problems expressing their opinion in front of the whole class?"; 3) "Are your students happier expressing their opinion when they work in pairs?"; 4) "Are your students willing to express their opinion or they wait for your stimulating questions and/or motivating remarks?”

\section{Research Methods and Procedure}

The results of semi-structured interviews depend on the informants' knowledge (Datko, 2015), which made it reasonable to turn to a method of 'keyinformant interviews' borrowed from the field of sociocultural anthropology (Duranti, 1997). The method implies selecting knowledgeable individuals who can provide reliable information about particular areas (Kottak, 2002), such as the teachers selected for this study. The second factor helping to select teachers as key informants for the interviews, apart from widely-recognized qualifications, was the fact that all of them work with the students of the Faculty of Computer Science and could provide first-hand and trustworthy information about the students for the study. To interpret data obtained by the questionnaire for students and from interviews with teachers the study employed both quantitative and qualitative research methods.

\section{Results}

The results of the survey show that the majority of interviewed teachers attribute students' problems with explaining and paraphrasing to the students' level of language proficiency. However, many of them also report that students often simply neglect the necessity to explain their ideas and thoughts further, providing details and/or paraphrasing. $48 \%$ of students, in their turn, are sure that they are able to communicate their message in the first sentence and no paraphrasing or additional information is required. A considerable number of students, $43 \%$, reported that they need stimulating questions or remarks from their teacher/examiner showing that there is actually a need to explain or paraphrase. $92 \%$ of students do not explain or paraphrase because they do not think it is necessary or simply because they wait for their teachers to motivate them to do so.

Interviewed students, as well as teachers, report that they experience serious problems expressing their opinion. Only 4 out of 10 teachers and 5 students out of 60 support the statement that students have no difficulties in expressing their opinion freely. The majority of students $(53 \%)$ highlight that they wait for the teacher's/examiner's invitation to express opinions, $43 \%$ of students claim to be too shy and $18 \%$ find expressing their opinion difficult because of the language skills that they need to develop. Interviewed teachers, sharing an observation from their teaching practice, state that their students are more willing and relaxed expressing group opinion rather than their own. Moreover, teachers point out that students feel comfortable exchanging their opinion in pairs or in groups rather than stating it in front of the whole class.

Only $15 \%$ of students report that they can easily sum up their ideas, while a significant number of students - 28 or $47 \%$ - find it difficult to summarise. $38 \%$ of students consider summarising "a waste of time" because they feel forced to repeat the ideas they have already expressed earlier. Interviewed teachers attribute problems with summarising among the students mainly to the lack of language skills essential for it. Teachers also point out that many students do not realize the importance of summarizing and complain that their students often forget to sum up.

Providing personal information such as name, nationality, address does not appear to be embarrassing for the majority of students (95\%). However, $80 \%$ of interviewed students are not willing to talk about their family background, childhood memories and life goals. Interviewed teachers, on the contrary, do not report these topics to be "unsafe" to discuss with their students. The answers and comments given by both students and their teachers are summarized in Table 1.

Perceptions by teachers and students of the reasons for the inefficient use of the speech functions are mostly not aligned, as can be seen from Figure 1 which illustrates the percentage of teachers and students attributing the inefficient use of the speech functions to a low language level. The speech function which is viewed in a relatively similar way is "providing personal information", only $3 \%$ of students and $5 \%$ of teachers see the difficulties in using this function and attribute them to the lack of language knowledge. Similarly, summarizing is seen as an important speech function that $47 \%$ of students admit not being able to use because they "have not practiced enough" and/ or "lack appropriate vocabulary and grammar". As claimed by the majority of the interviewed teachers, the remaining speech functions cause problems mainly for those students who demonstrate a low language level and lack language skills essential for explaining and paraphrasing, expressing opinion and summarizing: although the students themselves see different reasons for it (see Table 1 . Students and their teachers commenting on the use of four speech functions). The biggest gap in the percentage of teachers and students is observed when the participants comment upon the speech function "expressing opinion". Unlike 70\% 
Table 1

Students and their teachers commenting on the use of four speech functions

\begin{tabular}{|c|c|c|}
\hline Speech Functions & Teachers & Students \\
\hline Explaining and Paraphrasing & $\begin{array}{l}\text { Complain that many students "do not bother to } \\
\text { explain or paraphrase" even if it is necessary ( } 6 \text { out } \\
\text { of } 10 \text { teachers) } \\
\text { Point out that students lack language skills } \\
\text { essential for explaining and paraphrasing ( } 8 \text { out of } \\
\text { 10) }\end{array}$ & $\begin{array}{l}\text { Claim that they make it clear from the } \\
\text { very beginning ( } 29 \text { out of } 60 \text { students - } \\
48 \% \text { ) } \\
\text { Highlight that they lack appropriate } \\
\text { grammar and vocabulary ( } 24 \text { out of } 60 \text { - } \\
40 \% \text { ) } \\
\text { Point out that they are ready to explain } \\
\text { and paraphrase if their teacher/examiner } \\
\text { asks them to do so ( } 26 \text { out of } 60 \text { - } 43 \% \text { ) } \\
\text { Report that they experience no problems } \\
\text { explaining and paraphrasing ( } 8 \text { out of } 60 \\
-13 \% \text { ) }\end{array}$ \\
\hline
\end{tabular}

Expressing Opinion $\quad$ Highlight that students are more willing to express group opinion rather than their own (6 out of 10) Outline that students are more willing to express their opinion when they are ready to speak on the topic ("they know the topic vocabulary", "they know and can use the cliché phrases freely to express opinion" (7 out of 10 )

Report that some students are "too shy" to express their opinion in front of the whole class" (4 out of 10)

Point out that students have no problems expressing their opinion freely (4 out of 10 )

Point out that students lack language skills essential for summarising ( 6 out of 10)

Highlight that students do not realize the importance of summarising (5 out of 10)

Complain that many students "seem to forget to sum up" (4 out of 10)

\begin{abstract}
Report that there are some taboo topics that they avoid discussing with their students, e.g., politics, religion, sex, salary (10 out of 10)

Highlight that students are usually willing to provide personal information and do not avoid talking about family background, childhood memories, likes and dislikes, and life goals (7 out of 10)

Point out that very few students lack language skills to provide personal information but some students lacking language skills sometimes exploit the term "a taboo topic" as an excuse for their poor performance (3 out of 10 )
\end{abstract}

Highlight that they express their opinion only if their teacher/examiner asks them to do so (32 out of 60 students - 53\%) Point out that they experience difficulties in expressing their own opinion because they are shy (26 out of $60-43 \%$ )

Believe that they lack appropriate grammar and vocabulary to express their opinion (11 out of $60-18 \%$ )

Report that they have no problems expressing their opinion (5 out of 60 $8 \%)$

Report that they avoid summarising because they consider it a "waste of time" ( 23 out of 60 students $-38 \%$ )

Point out that they lack language skills essential for summarising (28 out of 60 $-47 \%)$

Consider summarising an important skill for the IELTS Speaking Test (9 out of 60 $-15 \%)$

Report that they experience no problems summarising ( 9 out of $60-15 \%$ )

Report that they do not mind providing personal information such as name, nationality, address and do not lack language skills to do it (57 out of 60 95\%)

Admit lacking appropriate vocabulary and grammar to provide personal information (3 out of $60-5 \%$ )

Point out that there are taboo topics that they are not willing to discuss and find embarrassing. Among them the most frequently named topics are politics, religion, family background, childhood memories and life goals (48 out of $60-$ $80 \%)$

Consider providing personal information "a kind of a human touch that helps to create a positive atmosphere for communication" (1 out of $60-2 \%$ )

of teachers, who believe that the problems students encounter using this function are linguistic in origin, the majority of students express different views, and only $18 \%$ of students share the vision of the problem with their teachers.

\section{Discussion}

The results from the survey show that apart from the lack of the language knowledge, namely, the lack of appropriate vocabulary and grammar, there are other factors of a sociocultural nature that influence students' outcomes and their performance during the IELTS Speaking Test. Having analyzed the responses given by students and their teachers, we could observe that the majority of the interviewed teachers underestimate the influence of sociocultural factors 


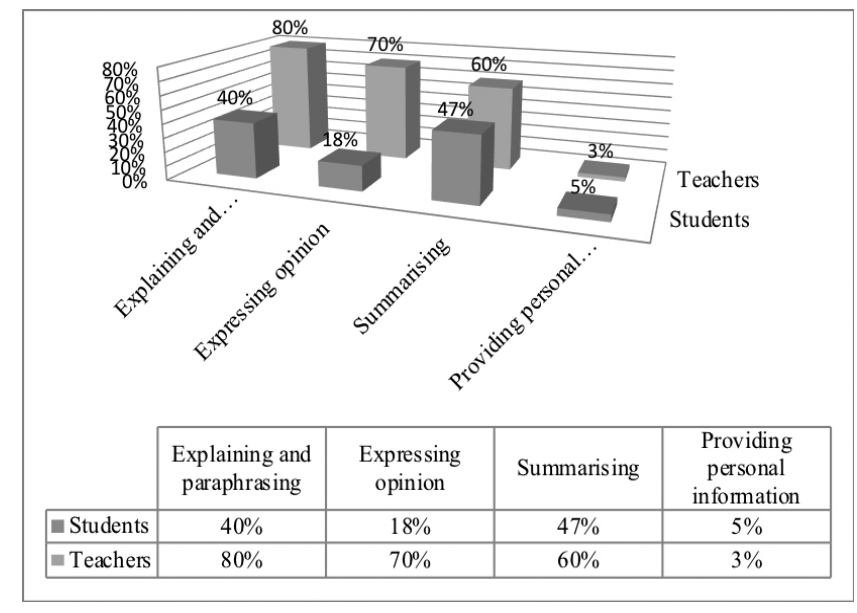

Figure 1. The percentage of teachers and students attributing the inefficient use of the speech functions to a low language level.

on students' outcomes and see the development of students' linguistic competence in a foreign language as a matter of dominant concern. On the contrary, the majority of students participating in the survey demonstrated a different and sometimes opposing view on the reasons causing problems with the use of the speech functions. These reasons mentioned by students and some of their teachers can be defined as those connected with sociocultural traditions and behavioral patterns in speaking and communication typical for Russian learners. Among them the following sociocultural reasons were mentioned most frequently: 1) the need for stimulating questions/or questions for details to motivate the speaker to explain further or paraphrase so that the matter, the situation or event is clear for the communication partner; 2) the willingness and readiness to express group opinion rather than your own; 3) seeing summarising as a "mere repetition" and " a waste of time", and 4) experiencing problems discussing taboo topics among which the students name politics, religion, family background, childhood memories and life goals. Though the limitations of the study do not allow to see if these sociocultural factors always come into play in every group of Russian learners and may require a bigger-scale research, the results of the present survey are sufficient to conclude that the problems students encounter using the speech functions could be solved with the help of approaches, teaching practices and tasks targeted at developing students' intercultural communicative competence and sociocultural competence as one of its structural elements.
Given an increasing number of Russian students who choose to work in multicultural companies both in Russia and abroad, it is essential for teachers to find ways to increase the students' level of sociocultural competence that would allow them to communicate effectively and to be able to fit into a multicultural team structure as required by the majority of leading international employers.

The results of the conducted study prove that the problems Russian students encounter using the speech functions are caused by the students' sociocultural background and should not be attributed only to their low language proficiency level, as is generally assumed. The way they tend to explain, paraphrase, summarise, express their opinion and provide personal information is also culturally defined which influences their ability to perform these functions during the IELTS Speaking Test.

To guarantee the efficient use of the speech functions required for the IELTS speaking exam a teacher/IELTS instructor would need a variety of sociocultural problem-based tasks and tests that are to be designed specifically for the format of the IELTS exam. The tasks and tests of this type should aim to develop students' sociocultural awareness that eventually can be turned into appropriate sociocultural performance at the exam.

\section{References}

Brown, H. D. (1994). Understanding research in second language learning: A teacher's guide to statistics and research design. Cambridge, UK: Cambridge University Press.

Byram, M. (1997). Teaching and assessing intercultural communicative competence. Clevedon, UK: Multilingual Matters Ltd.

Byram, M., Zarate, G., Neuner, G. (1997). Sociocultural competence in language learning and teaching: Studies towards a common European framework of reference for language learning and teaching. Strasbourg, France: Council of Europe Publishing.

Byram, M., Nichols, A., \& Stevens, D. (2001). Developing intercultural competence in

practice. Clevedon, UK: Multilingual Matters Ltd.

Cohen, L. (2007). Research methods in education. New York, NY: Routledge.

Cohen, A. D., \& Olshtain, E. (1981). Developing a measure of sociocultural competence: The case of apology. Language Learning, 31, 113-134. Retrieved from http://dx.doi.org/10.1111/j.1467-1770.1981. tb01375.x

Datko, J. (2015). Semi-structured interview in language research pedagogy. Journal of Language and Cultural 
Education, 3(2), 142-155.

Deardorff, D. K. (2006). The identification and assessment of intercultural competence as a student outcome of internationalization at institutions of higher education in the United States. Journal of Studies in International Education, 10(3), 241-266.

Duranti, A. (1997). Linguistic antropology. Cambridge, UK: Cambridge University Press.

Elizarova, G. (2005). Cultura i obuchenie inostrannym yazykam [Culture and Foreign Language teaching]. St. Petersburg, Russia: KARO.

Fulcher, G. (2003). Testing second language speaking. London, UK: Person Education Limited.

Gibson, C., \& Swan, A. (2008). The significance of sociolinguistic backgrounds of teachers of IELTS Test preparation courses in selected Malaysian institutions. Retrieved from https://www.ielts. org/-/media/research-reports/ielts_rr_volume08 report2.ashx

Johnson, K. E. (2009). Second language teacher education: A sociocultural perspective. London, UK: Routledge.

Holmes, P., \& O'Neill, G. (2012). Developing and evaluating intercultural competence: Ethnographies of intercultural encounters. International Journal of Intercultural Relations, 36, 707-718.

Kottak, C. P. (2002). Anthropology. The exploration of human diversity (9th ed.). Boston, MA: McGraw-Hill.

Kramsch, C. (2004). Context and culture in language teaching. Oxford, UK: Oxford University Press.

Leontovich, O. (2002). Russkie $i$ amerikantsy: Paradoksy mezhkul'turnogo obschenija [Russians and Americans: Paradoxes of intercultural communication]. Volgograd, Russia: Peremena.

Mak, A. S. (2011). Facilitating intercultural interactions to enhance international students' psychosocial adjustment. Retrieved from https://psychology. org.au/facilitating-intercultural-interactionsenhance-international-students-psychosocial- adjustment

Mak, A. S., Westwood, M. J., Ishiyama, F. I., \& Barker, M. (2000). The sociocultural competencies for success among international students: The Excell program. Journal of International Education, 4(2), 33-38.

Murray, J. C., Cross, J. L., \& Cruickshank, K. (2014). Stakeholder perceptions of IELTS as a gateway to the professional workplace: The case of employers of overseas trained teachers. IELTS Research Report Series, 1, 34-37. Retrieved from https://www. ielts.org/-/media/research-reports/ielts_online_ rr_2014-1.ashx

Nunan, D. (1992). Research methods in language learning. Cambridge, UK: Cambridge University Press.

Paulus, T. M., Bichelmeyer, B., Malopinsky, L., \& Rastogi, P. (2005). Power distance and group dynamics of an international project team: A case study. Teaching in Higher Education, 10, 43-55.

Safonova, V. V. (2014). Co-learning of languages and cultures in the mirror of world tendencies: Developing modern language education. Language and Culture, 1, 109-126.

Safonova, V. V. (2008). Sociocultural aspects of language education. Moscow, Russia: Euroschool.

Sternina, M., \& Sternin, I. (2003). Russian and American communicative behavior. Voronezh, Russia: Istoki.

Vassilieva, I. (1998). Who am I / Who are we in academic writing. International Journal of Applied Linguistics, 8(2), 163-190.

Valeev, G. H. (2002). Metodologiya i metody psihologopedagogicheskih issledovaniy [Methodology and methods of psychological and pedagogical research]. Sterlitmak, Russia: Sterlitmak State Pedagogical Institute.

Wierzbicka, A. (1997). Understanding culture through their key words. English, Russian, Polish, German and Japanese. New York, NY; Oxford,UK: Oxford University Press. 


\section{GALINA PAVLOVSKAYA, ANASTASIA LORD}

\section{Appendix 1}

\section{Student's Questionnaire}

Speech Functions for the IELTS Speaking Test

Tick what is true for you from 1-4 or write your own answer in the blank space:

\section{Explaining and paraphrasing}

1. I always make it clear from the very beginning. There is no need to explain further or paraphrase what I say.

2. Sometimes I need to explain or paraphrase but I lack appropriate vocabulary and grammar.

3. I can always explain and paraphrase if the examiner/teacher asks me to do so/ I can do it easily using appropriate vocabulary and grammar.

4. Every time I need to explain or paraphrase I can do it easily using appropriate vocabulary and grammar.

5.

\section{Expressing opinion}

1. I do not hesitate to express my opinion. I can do it easily using appropriate vocabulary and grammar.

2. It can be difficult for me to express my opinion because I lack appropriate vocabulary and grammar.

3. I am shy and it can be difficult for me to express my opinion, especially in front of the whole class.

I I would express my opinion if I have something important or interesting to say or if the examiner/teacher asks me to

4. do so. I can do it easily using appropriate vocabulary and grammar.

5.

\section{Summarising}

1. I can always summarise ideas, facts and figures using appropriate vocabulary and grammar.

2. It can be difficult for me to summarise ideas, facts and figures because I lack appropriate vocabulary and grammar.

3. I avoid summarising. I think summarising involves repeating and retelling the ideas and facts that have already been

3. mentioned. It can be a waste of time.

4. I think summarising is an essential skill for the IELTS Speaking Test and it makes your answer logical and well-

4. structured.

5.

\section{Providing personal information}

1. I do not mind providing personal information if the procedure of the exam requires me to do so. I would not mind any personal questions about my family background, my life goals or my likes and dislikes.

I do not mind providing personal information if the procedure of the exam requires me to do so. I would avoid

2. answering some personal questions about my family background, my life goals or my likes and dislikes.

3. I find it embarrassing to provide personal information or to answer personal questions from examiner/the teacher. It can also be difficult for me to answer them because I lack appropriate vocabulary and grammar.

4. I do not mind providing personal information if the procedure of the exam requires me to do so. I would not mind personal questions. It can only be difficult for me to answer them because I lack appropriate vocabulary and grammar.

5.

Please write if there are topics that you are unwilling to discuss during the IELTS Speaking Test because you find them embarrassing. 